\title{
DEVASSANDO SILÊNCIOS DA POÉTICA DE ORIDES FONTELA
}

\section{UNVEILING SILENCES IN ORIDES FONTELA'S POETICS}

\author{
Lucas de Sousa Serafim ${ }^{1}$
}

\author{
Atraidas e traídas \\ atraímos e traímos \\ Nossa tarefa: fecundar \\ atraindo \\ nossa tarefa: ultrapassar \\ traindo \\ o acontecer puro \\ que nos vive. \\ Nosso crime: a palavra. \\ Nossa função: seduzir mundos. \\ Deixando a água original \\ cantamos \\ sufocando o espelho \\ do silêncio.
}

Orides Fontela - As sereias

RESUMO: Este artigo pretende observar a produção literária da poeta brasileira Orides Fontela, buscando sinais da maneira pela qual a artista concretiza os silêncios em sua escritura. O silêncio não é observado como uma força diversa ao som, como se uma eliminasse a outra, mas como forças paralelas e de igual valor. Ou seja, complementares. Desse modo, é possível salientar como os espaços vazios, os silêncios, as opções da poeta em suprimir a verborragia também são um instrumento eficaz de expressão.

PALAVRAS-CHAVE: ORIDES FONTELA; SILÊNCIO E SOM; CRISE NA/DA LINGUAGEM.

${ }^{1}$ Doutorando no Programa de Pós-Graduação em Literaturas da Universidade Federal de Santa Catarina (PPGLit-UFSC). 
ABSTRACT: This article intends to observe the literary production of brazilian poet Orides Fontela, searching for signs of the materialization of silence in her artistic writing. Silence and sound are not seen as diverse or mutually exclusive forces, but as parallel, equally valuable, and complementary forces. As such, it's possible to accentuate how the empty spaces, the silences, and the poet's choice to supress verbiage are also efficient expression tools.

\section{KEYWORDS: ORIDES FONTELA; SILENCE AND SOUND; CRISIS IN/OF LANGUAGE.}

\section{Ondas sonoras}

As ondas sonoras são captadas pelo ouvido conforme as vibrações que um objeto causa na atmosfera, chamadas hertz $(\mathrm{Hz})$. O ouvido humano é capaz de absorver e atribuir sentido às vibrações que variam na frequência entre $20 \mathrm{~Hz}$ e $20.000 \mathrm{~Hz}$. Um som, portanto, é aquilo que sentimos por meio do aparelho auditivo quando somos golpeados por essa frequência vibratória. É importante destacar que tal frequência necessita de um meio para se propagar - isto é, não é possível haver som no vácuo. Por denominação antropomórfica, qualquer onda menor que $20 \mathrm{~Hz}$ é denominada infrassom, enquanto as ondas que apresentam frequência maior que $20.000 \mathrm{~Hz}$ se chamam ultrassom. Tanto o infrassom quanto o ultrassom chegam até os ouvidos humanos, mas não são capazes de estimular o sentido de audição. Alguns animais conseguem captar essas frequências, muitas vezes utilizando-as para comunicação, como por exemplo os cães, gatos ou morcegos. Conforme a frequência os seres humanos entendem os sons como graves (frequência baixa) ou agudos (frequência alta).

Assim sendo, é o cérebro humano que interpreta e atribui sentido às ondas vibratórias produzidas no mundo. Quando tais vibrações obedecem a uma cadência que é harmônica aos nossos sentidos, podemos chamar de música. Conforme aponta José Miguel Wisnik:

\footnotetext{
A onda sonora obedece a um pulso, ela segue o princípio da pulsação. Bem a propósito, é fundamental pensar aqui nessa espécie de correspondência entre as escalas sonoras e as escalas corporais com as quais medimos o tempo. Porque o complexo corpo/mente é um medidor frequencial de frequências. Toda a nossa relação com os universos sonoros e a música passa por certos padrões de pulsação somáticos e psíquicos, com os quais jogamos ao ler o tempo e o som (WISNIK, 1989 , p. 19 - grifos no original).
}

Partindo dessa observação, podemos entender que música pode ser qualquer som que obedeça a uma cadência, chamada ritmo. Ou melhor, se os sons são emissões pulsantes passíveis de interpretação nos corpos, as músicas se fazem na intersecção de diversas 
frequências que se combinam e se interpenetram, estabelecendo relações complementares entre si. As frequências sonoras admitem diferentes faixas de ondulação, seja a duração (rítmica), seja a altura (melódico-harmônica); tal qual a pulsação humana admite ritmos somáticos (pulsação sanguínea) e ritmos psíquicos (ondas cerebrais). (WISNIK, 1989, p. 20) Ou seja, pode-se ampliar a percepção do que é música através da relação que se abre ao sentido, de modo complementar - e não excludente. Da mesma maneira que o corpo humano admite pulsações complementares para seu funcionamento, a música também admite.

Toda música se faz no contato das vibrações com o corpo humano - já que é o ser humano quem atribui significação às vibrações que lhe golpeiam, segundo as cadências. Partindo da colocação de Wisnik:

No entanto, é preciso lembrar que, em música, ritmo e melodia, durações e alturas se apresentam ao mesmo tempo, um nível dependendo necessariamente do outro, um funcionando como o portador do outro. É impossível a um som se apresentar sem durar, minimamente que seja, assim como é impossível que uma duração sonora se apresente concretamente sem se encontrar numa faixa qualquer de altura, por mais indefinida e próxima do ruído que essa altura possa ser (WISNIK, 1989, p. 21 grifos no original).

Pode-se concluir que todas essas nuances são complementares, isto é, uma não existe sem a outra. Retornando ao ponto inicial deste texto, uma vez que entendemos por som todas as vibrações que estão dentro de uma margem de frequência e, consequentemente, por silêncio aquilo que não alcançou o mínimo para estar nessa margem ou está para além dela, tanto som quanto silêncio ocupam o mesmo status para música. Ampliando tal reflexão, sendo um portador do outro, não é possível que haja um sem haver o outro.

Então, parto da problemática da maneira pela qual a literatura pode se apropriar dessa ferramenta - som e silêncio enquanto complementares - para ampliar suas possibilidades artísticas.

\section{Acústica}

Logo nos primeiros capítulos de O livro por vir Maurice Blanchot expõe uma alegoria da linguagem tomando como base "O canto das sereias". Esses seres mitológicos antropozoomorfisados, isto é, metade humano e metade animal (em algumas lendas são pássaros, mas em outras, mais conhecidas, peixes), as sereias possuem um canto doce e hipnotizador. O canto não satisfaz completamente a quem as ouve, apenas orienta para qual direção seguir com a finalidade de encontrá-las. Quando ainda está imperfeito ou ecoante, o 
canto das sereias conduz os marinheiros ao lugar onde, de fato, ele se realiza. É importante ressaltar que as sereias não enganam os marinheiros, mas os hipnotizam. Uma vez hipnotizados, os marinheiros seguem até a região onde o canto se realiza, entretanto, ali, tudo desaparece completamente.

Esse canto inumano, esse ruído aparentemente disforme, encanta. Encanta, conduz, atrai. Tudo isso porque é prazeroso, diverso do esperado, desnaturalizado. Ou ainda, uma imensa trama sonora em que o sentido é capaz de ser irrealizado. Como afirma Blanchot (2005, p. 04), há algo de maravilhoso no canto real das sereias, tal canto simples e cotidiano faz reconhecer potências estranhas e, por assim dizer, imaginárias, pode ser entendido como um canto do abismo que, uma vez ouvido, se abre em cada fala uma voragem e convida fortemente a nela desaparecer.

Tal vocalização produzida pelas sereias é um signo que porta em si vida e morte. É um convite, uma potência. Por isso, paralelamente, é possível refletir sobre o silêncio deste canto. Franz Kafka, na narrativa intitulada "O silêncio das sereias""2 também adentra em tal reflexão. O escritor afirma: “As sereias, entretanto têm uma arma ainda mais terrível que o canto: o seu silêncio". Certamente que o silêncio é tomado como mais terrível porque nele tudo pode ocorrer. Ao contrário da emissão dos sons que compõem as palavras, a qual elimina a impotência, o silêncio é a potência das palavras. Nele é possível que tudo se transforme. No som, não. O som elimina qualquer entendimento diverso ao que foi proferido.

O silêncio é matéria que está intimamente relacionada aos sons. Muitas vezes é entendida como contraposição de som. Entretanto, não é esta a premissa deste texto. Pretendo observar o silêncio não como exclusão do som, mas como matéria diversa e análoga ao ruído; fenômenos acústicos que ocupam lugares, ao mesmo tempo, diferentes e de semelhante importância, isto é, sem detrimento de um em função do outro ${ }^{3}$. Nesse sentido, tomarei como material de análise alguns poemas da escritora brasileira Orides Fontela. Muito embora a poesia tenha ligações com a lírica - gênero que se alinha à música - os escritos da autora chegam até o público por meio de livros, ou seja, de forma escrita (não sonora). Portanto, eis

\footnotetext{
2 "O silêncio das sereias" faz parte do conjunto de textos e fragmentos narrativos descobertos por Max Brod nos papéis póstumos de Kafka. Inicialmente, a narrativa não tinha título. Foi Max Brod quem atribuiu tal nome "Das Schweigen der Sirenen" [O silêncio das sereias]. Para este texto foi utilizada uma tradução publicada no jornal Folha de São Paulo em 1984, disponível em: <http://almanaque.folha.uol.com.br/kafka2.htm>. Acesso em: 02 fev. 2017.

${ }^{3}$ Parto, para tanto, de uma frase contida na narrativa Rumori o voci (narrativa de Giorgio Manganelli, publicada em 1987 pela casa editorial Rizzoli), a qual dialoga com os preceitos expostos anteriormente: "O silêncio não é a diminuição a zero do ruído, mas qualquer coisa de diversa, um outro lugar diferente do que o ruído" (Original: "Il silenzio non è diminuzione a zero del rumore, ma qualcosa di diverso, un altrove rispetto al rumore". MANGANELLI, 1987, p. 33 - tradução minha).
} 
mais um ponto a ser somando à problemática inicial, qual seja, a maneira pela qual os silêncios adquirem forma na poesia da autora.

Orides de Lourdes Teixeira Fontela nasceu em São João da Boa Vista em 1940 e faleceu em 1998, em Campos do Jordão. Orides Fontela iniciou suas publicações na sua cidade natal, em um suplemento literário do jornal $O$ Estado de São Paulo chamado $O$ município; pôde formar-se pela Universidade de São Paulo no curso de Filosofia; recebeu prêmios pela sua produção, com destaque para o livro Alba (1983), Jabuti de Poesia em 1983, e o livro Teia (1996), prêmio da Associação Paulista de Críticos de Arte, em 1996. Contudo, a solidão e depressão a acompanharam nos últimos anos de vida, juntamente com a escassez de dinheiro - esta companheira de toda vida, assim como seus gatos. Ao longo de seus 58 anos de vida, publicou Transposição (1969), Helianto (1973), Alba (1983), Rosácea (1986) e Teia (1996), que foram reunidos em 2006 em uma Antologia Poética, organizada por Augusto Massi e publicada pelas editoras Cosac Naify e 7Letras ${ }^{5}$.

Para este texto me valho de quatro textos poéticos: "Fala", "Poema", "Ode", "Esfinge". "Fala" foi publicado no primeiro livro da autora. O "Poema" escolhido é o segundo texto de Alba. Do penúltimo, Rosácea, escolhi a "Ode" e "Esfinge". A escolha dos textos se deu por meio do eixo temático, embora não tenha sido difícil porque há muitos poemas da autora que tratam do silêncio. Mesmo não sendo o foco principal traçar uma cronologia, pretendo refletir sobre a composição do tema por meio de sua intensidade na trajetória da autora.

\section{Som}

Os quatro textos poéticos escolhidos, de alguma forma, tematizam o silêncio. "Fala" é composto por 17 versos, divididos em 5 estrofes; é o maior texto dentre os quatro que compõem o corpus deste artigo. Foi publicado em 1969 em Transposição, livro que contém textos com essas características - ainda longos, se comparados com o conjunto da obra; ele é composto por quatro partes: Base, $(-),(+)$ e Fim. Em Transposição já estão contidos os elementos que acompanharão a escritura poética de Orides, tais como os temas, a maturidade de sua escrita, versos que dialogam com correntes teóricas e filosóficas contemporâneas etc. Mas, sobretudo, a desconstrução da palavra, isto é, a dificuldade do trabalho com a linguagem

\footnotetext{
${ }^{4}$ Pequeno município a centro-leste no estado de São Paulo com cerca de noventa mil habitantes.

${ }^{5}$ FONTELA, Orides. Poesia Reunida [1969-1996]. São Paulo: Cosac Naify; Rio de Janeiro: 7 Letras, 2006.376 p.
} 
- e isto aparece no poema escolhido. A partir de tal trabalho de desconstrução e reconstrução da linguagem, a poeta é capaz de apontar para a busca da essência dos sentidos da palavra. É por meio desse trabalho que Orides Fontela devassa o signo poético, buscando o sentido mais primário da palavra.

Os "movimentos" que compõem o livro chamam atenção. A "Base", primeira parte da publicação, é o espaço em que a consciência do trabalho com a linguagem fica mais evidente. Em “(-)" é possível perceber o desdobramento dessa consciência, transformado em crise da/na linguagem, sinalizado, sabiamente, pelo sinal gráfico-matemático. "Fala" abre esse segundo movimento:



(Toda palavra é crueldade.)

É interessante destacar como o último verso corrobora a ideia de crise da/na linguagem. Outro ponto interessante, ainda, é que o verso "toda palavra é crueldade" está grafado entre parêntesis, recurso sintático muitas vezes utilizado quando pretende-se fazer um comentário ao texto principal.

Um fator importante a ser delineado é que aqui surge outro tema que vai acompanhar toda a escritura de Orides: a tentativa de aproximação da palavra e do seu referente no mundo. Porém essa tentativa já aponta para sua frustração, uma vez que "Tudo/ será difícil de dizer", como assinala a escritora na primeira estrofe.

O próximo movimento deste livro é oposto ao anterior. Em “(+)" a poeta se rende às armadilhas da palavra (BUCCIOLI apud FARIA, 2014, p. 10). Aqui o silêncio começa a ser 
apontado por meio do re-tecer a trama poética, isto é, alguns versos são repetidos em estrofes seguidas, mas com pequenas diferenças, dando a impressão de "ecos" no poema, ressignificando o que foi dito, silenciando o que foi exposto. E, no movimento final de Transposição, intitulado "Fim", há uma retomada do percurso realizado no livro. Novamente há uma característica de sua obra, o movimento em espiral. Em vários livros, assim como em toda sua obra, há uma recuperação de temas, como o de um movimento circular.

No primeiro livro da autora é possível perceber a maturidade da poeta que se põe em uma incansável batalha entre o ser e a linguagem. Através desse embate, pouco a pouco, corrobora-se a hipótese de que somente no silenciamento da palavra é que ela, efetivamente, pode se fazer.

Alba é publicado em 1983, recebe o prêmio Jabuti de poesia e traz o prefácio assinado por Antonio Candido. Nessa publicação, Orides Fontela continua seu (infindável) trabalho poético caracterizado pela tensão entre linguagem e mundo. Passados quatorze anos - quase metade de sua trajetória reconhecida pela crítica - ainda permanecem os textos longos, como se percebe em "Poema":

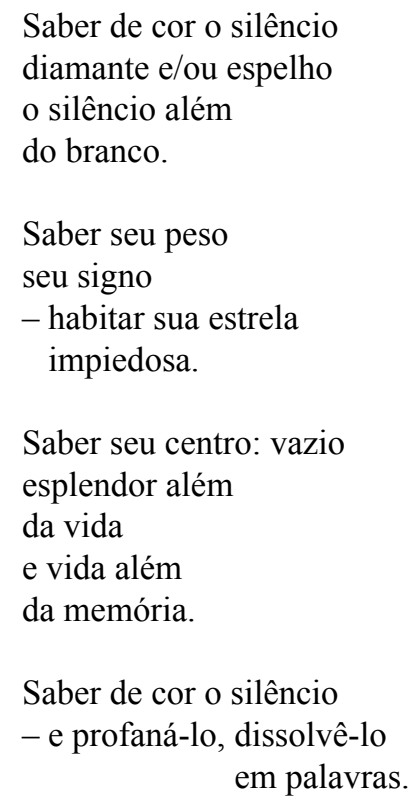

O texto apresenta 16 versos divididos em 5 estrofes. Entretanto, a forma já começa a chamar atenção. Os versos ficam disformes: alguns longos, com 7 sílabas poéticas, com 5 palavras; alguns curtos, com 3 sílabas poéticas, 1 única palavra. Os espaços em branco adentram o poema, afastando a grafia da margem (versos 8 e 16, por exemplo), assim como os sinais gráficos invadem a escrita ("barra" no segundo verso e "travessão" nos 7 e 15). Essas 
características começam a saltar aos olhos, numa tentativa de sinalizar o silenciamento, resultado da tensão entre linguagem e realidade. Como sugere a última estrofe do "Poema", dessa maneira é possível profanar o silêncio. É possível perceber que ainda permanece o trabalho da tentativa de "polir" a linguagem, diminuir sua frequência vibratória ao ponto de não ultrapassar a margem audível humana, permanecer no silêncio.

A primeira estrofe termina sinalizando que o silêncio está além do branco. Aqui há uma intersecção plausível, a associação do silêncio sonoro com o branco da página. Orides continua sua poesia destacando que esse gesto é um signo, portador de um peso. Como se fosse pesado dar liberdade a potência - tanto do som quanto da escritura. Assim, somente ao final, seria possível dissolver em palavras esse vazio para onde o signo se abre.

Três anos mais tarde, 1986, Rosácea é publicado apresentando características estruturais bastante diversas dos livros anteriores. Aqui surgem os poemas curtos e curtíssimos:

\author{
Neste tudo \\ tudo falta \\ (neblina) \\ e nesta \\ falta: eis \\ tudo.
}

Essa "Ode" apresenta 6 versos separados em 3 estrofes, uma estrofe com apenas um verso contendo uma palavra; Essa “Ode" é grafada abaixo de outro poema, portanto aparece no livro do meio da página para baixo. O uso excessivo do recurso poético enjambement se torna evidente, como se no próprio verso não coubesse mais o sentido que a poeta gostaria, como se no verso não fosse possível finalizar seu sentido, enfim, como se houvesse necessidade de prolongar suas vibrações.

A “Ode" escrita pela autora parece sair da mesma receita dos poemas de João Cabral de Melo Neto, em que a economia lexical é evidente, destacando pronomes (categoria de palavras que recupera substantivos sem nomeá-los) e vocábulos que transitam pelas classes gramaticais. Exemplifico: a grafia de "falta" no poema ora se comporta como verbo, ora como substantivo; "tudo" é pronome, comportando-se como indefinido em alguns versos e como neutro em outros; os demonstrativos também ocupam espaço no texto. Em suma, considerando as características morfossintáticas, o que há de invariável e substancial no 
poema é a segunda estrofe - a qual inevitavelmente chama atenção pela sua forma. Essa estrofe apresenta somente o vocábulo "neblina". Neblina é um fenômeno meteorológico que priva a visibilidade, ou seja, quando ocorre neblina as coisas não podem ser vistas nitidamente. Ainda, o vocábulo está grafado entre parêntesis, cujo uso sinaliza comentários paralelos ao texto principal, uma informação acessória (conforme supracitado). É possível analisar o texto que começa apontando para as ausências e finaliza destacando que é justamente nelas que tudo pode ocorrer - assim como o conceito de silêncio que guia este artigo. A neblina, aqui, serve como possibilidade diversa da natural, ou seja, a partir da supressão da visão naturalizada, tudo pode ser verificado. Um exemplo de tal tema pode ser visto no próprio texto, o vocábulo "falta", na primeira estrofe ele é verbo, após a "neblina" ele se torna substantivo - movimento que ultrapassa a morfossintaxe e se instaura como tema: no todo não há nada, e, justamente aí, há tudo.

A “Ode” compõe a terceira parte (Bucólicos) do livro Rosácea, são elas: Novos, Lúdicos, Bucólicos, Mitológicos e Antigos. Os Antigos são compostos por sonetos datados da década de 1960, textos mais distantes de toda a composição curta e fragmentada que dá forma ao livro. Dentro da categoria dos Mitológicos se encontra o texto "Esfinge":

\footnotetext{
Não há perguntas. Selvagem o silêncio cresce, difícil.
}

Vale destacar que esse poema se apresenta sozinho na página. $\mathrm{O}$ espaço em branco complementa a tinta impressa. O que se lê somente na parte superior da folha ecoa no branco do papel. A estrutura dessa obra é simples: dois versos compostos por quatro vocábulos cada; em cada verso há um molde: três palavras, uma pausa (ponto, vírgula), outra palavra. Levando em consideração a assertiva que exponho aqui, de que os sinais gráficos de pausa e os espaços em branco dão forma aos silêncios como resultado da tensão entre linguagem e mundo, um olhar para o texto expõe a expansão desta característica. O primeiro sinal de pontuação que sinaliza pausa encerra a primeira oração; em seguida, em uma narrativa, o esperado seria que a próxima oração estivesse toda em uma única linha, entretanto não está. $O$ uso do enjambement rompe com essa naturalidade: a estrutura do verso marca seu fim, mas o sentido não; há uma suspensão do sentido, o qual é lançado para o verso seguinte. O ritmo de leitura também marca essa suspensão. Isto é, ao ler uma frase curta, pausar a leitura por causa do ponto, voltar a ler outra frase que é cindida pela escrita em versos, novamente pausar antes da 
palavra final, esse ritmo apresenta uma evolução da suspensão que, posteriormente, ocupa toda a página, que foi deixada em branco. Essas marcas de suspensão destacadas comunicam tanto quanto as palavras. Eis o silêncio, grafado.

Além da forma, o conteúdo do texto também chama atenção. O título recupera um signo que está presente em algumas culturas - novamente um ser antropozoomorfisado. $\mathrm{O}$ mito mais conhecido que envolve a esfinge é descrito na peça "Édipo rei”, de Sófocles. "Decifra-me ou devoro-te" era o que o ser dizia antes de proferir seu enigma, quem não o decifrava era estrangulado pela criatura. Quando Édipo decifrou o enigma, a lenda diz que a Esfinge se atirou de um precipício. Este relato é recuperado no texto, porém desarticulado: cada leitor se coloca diante da Esfinge de Orides, mas "não há perguntas"; "o silêncio que cresce, difícil", é o próprio enigma que a poesia expõe; o precipício para onde a criatura se atira pode ser o enjambement, ou o próprio espaço em branco que invade a página após o final do texto.

\section{Silêncios}

A obra da poeta Orides Fontela, muitas vezes, é vista como concisa e contundente, e também com tendências metafísicas e filosóficas. Ainda é pouco conhecida e apresenta uma fortuna crítica não muito vasta, embora tenha sido avaliada e reconhecida por diversos críticos e estudiosos, tais como Marilena Chauí, Antonio Candido, Alcides Villaça, Benedito Nunes, Augusto Massi, Ivan Junqueira e Davi Arrigucci Jr (cf. FARIA, 2014). Antonio Candido, conforme supracitado, é quem assina o prefácio de Alba e Marilena Chauí, de Teia. Alguns estudiosos destacam pontos de contato entre a obra da poeta e uma tradição poética e filosófica composta por nomes como Mallarmé, Valéry, Ungaretti e Heidegger (LOPES, 2008, p. 115). Orides Fontela é uma autora que vem de uma tradição da poesia concreta brasileira, entretanto ela não se encaixa completamente nos preceitos deste movimento, ela se fecha nas correntes brasileiras elencadas pelos historiadores literários brasileiros durante os anos de sua produção - 1970 com tendências concretistas e, posteriormente, neoconcretistas, 1980 com tendências sociais. Quando comparada a outras poetas brasileiras, Orides parece estar em um momento de transição entre tendências mais fortes, tais como o rompimento com a lírica de Cecília Meireles e antecedendo o momento da literatura marginal de Ana Cristina César. Pode, portanto, ser comparada a uma produção de cunho intimista (assim como acontecia com a narrativa de Clarice Lispector, por exemplo), tendo sua produção associada à 
de Adélia Prado - mais pelo caráter do que pela temática (cf. ZILBERMAN, 2004). Sua obra, então, não pode ser perfeitamente associada às coordenadas estéticas do período de produção e tampouco atende às demandas de ferramentas teóricas com as quais, frequentemente, se enfrenta e se avalia uma produção. Este fato sugere, portanto, uma reavaliação dos arcabouços teóricos convencionais.

A poética de Orides Fontela subverte. Reorienta estruturas morfossintáticas; reorienta produção literária; reorienta, em última instância, metodologia de enfrentamento da obra. Mas, como já foi exposto, a produção da poeta não paira sozinha no universo literário, está associada a uma corrente de "crise na/da palavra", da qual a literatura poética universal vinha se aproximando com nomes como José Bergamín, Antonio Machado, Eugenio Montale, Umberto Saba, Giorgio Caproni, Manuel Bandeira, Carlos Drummond de Andrade, João Cabral de Melo Neto, entre outros. A palavra em crise se abre para novos caminhos, novas possibilidades de expressão. Como bem salienta Bergamín (2006), a ausência da racionalidade pura compromete o jogo semântico das palavras, isto é, o esquema referencial "palavra-mundo", que muitas vezes é estabelecido de modo urgente e automático, não é suficiente para abarcar toda a complexidade envolvida nesta relação. As palavras são enferrujadas; a relação que se estabelece pode se renovada. E, assim, há um abandono do abuso da razão. Para exemplificar, podemos pensar na imagem de um leque; quando o leque se encontra fechado a imagem que se mostra é automática, única, pequena e (até) eficiente; mas, com um olhar mais atento é possível perceber que a imagem na haste de um leque não é o suficiente; então, quando se abre o artefato é possível ver que há desdobramentos da imagem automática: singular, grande, eficiente. Tem-se, portanto, a palavra automatizada, naturalizada, sendo a face do leque fechado; paralelamente à relação entre as palavras, a palavra deslocada de seu lugar natural, reestruturada, pensada. A naturalização põe em ordem enquanto os desdobramentos põem em caos.

A produção poética advinda dessa corrente que compreende a palavra em crise é o canto das sereias. Porém, um canto poético posterior ao silêncio delas, sinalizado por Kafka. Orides Fontela - e os outros poetas - pode ser comparada a personagem Orfeu, mas a um detalhe pequeno e quase despercebido no relato do mito: o poeta e músico protagonista, antes do grande feito nos Infernos, durante as navegações, usava sua arte para silenciar as sereias impedindo que seus companheiros navegantes fossem afetados pela melodia mortal dos seres marinhos. Enquanto a palavra mata (cf. BLANCHOT, 2006), os poetas silenciam a potência 
de morte contida nas palavras. O canto das sereias, agora, é atração e traição. Atrai puxando violentamente para si, prendendo a atenção de quem lê o texto porque a compreensão não se dá de modo automático. Trai empurrando a pessoa que lê para os abismos da poesia, desconfortando, deslocando da naturalidade de entendimento, instaurando o caos. Por causa disso tudo que os espaços em branco comunicam tanto quanto a palavra grafada, as lacunas podem ser entendidas como os silêncios, único resultado possível do embate da crise da palavra. O olhar voltado para os vazios pode sinalizar a singularidade do objeto artístico, a devolução de sua qualidade única diante da era de reprodutibilidade técnica, sinalizada por Walter Benjamin. Os silêncios podem ser uma guerrilha contra os sons produzidos automaticamente na multidão.

É possível perceber na trajetória literária de Orides Fontela que os espaços em branco, os silêncios, vão adquirindo forma e vigor porque o fazer poético em sua escritura é sempre o desfazer e refazer. Essa possibilidade é uma tentativa de alcançar o instante, a sensação vivida, que a palavra não é capaz de expressar completa e perfeitamente. Portanto, inevitavelmente, paira no ar uma tensão entre a linguagem e os fatos, os eventos. A única maneira que a poeta encontra para transcrever essa tensão é por meio dos silêncios, representados por espaços em branco, por símbolos, etc. Orides-poeta alude ao instante, à sensação, ao evento. Alude porque é consciente que sua tentativa de se aproximar do que seria a coisa em si é em vão. Mas, mesmo assim, ela busca incansavelmente o limite da palavra. Sendo, portanto, a palavra uma profanação do estado ideal, como se o "dizer" não pudesse ser dito, apenas sugerido, aludido. O texto passa a representar a violação do instante. Sua busca é por uma fresta, uma rachadura, por onde a palavra possa penetrar e capturar o momento.

A vasta utilização de símbolos serve como ferramenta em que a poeta alude sem a necessidade de dizer. Isto é, mais uma forma de silenciar. Os símbolos aparecem na nomeação das partes dos livros (Transposição), na nomeação de textos ("Esfinge"), sendo um modo de evocar o relâmpago da razão, a naturalidade do símbolo. Porém, ela subverte este símbolo, instaura o caos, desloca-o, movimenta-o, enfim, ressignifica-o (como no segundo verso do "Poema" com a utilização da "barra"; ou pelo uso dos parêntesis, por exemplo). O símbolo ultrapassa o status de enigma e ocupa o lugar de mistério, em que haverá a necessidade de investigar as pistas que a autora demonstra e sugere em seus textos. Embora não haja uma ligação tão direta, a opção pela utilização de símbolos pode ser vista sob a perspectiva dos haicais, isto é, a forma de poesia oriental que pretende expor a plasticidade, buscando realizar 
flashes do cotidiano. Certamente que esse modus operandi revela as raízes concretistas da poeta. Essa ferramenta desautomatiza o olhar, faz com que a pessoa que lê seja obrigada a permanecer em estado de alerta, uma vez que o símbolo está mais ligado ao emblema do que à senha.

O ritmo dos textos geralmente é circular (na “Ode", por exemplo). Ou seja, por meio de ecos, recuperação de palavras, retomada de temas, a autora avança em sua trajetória literária retornando. Um movimento circular. Assim, é possível que se interligue poemas, um poema sugere outro(s). Dessa maneira o ritmo se instaura também como símbolo. Um desses símbolos que se pode pensar são os caleidoscópios, aparelhos óticos com fragmentos de vidro colorido que, por meio da interação da luz exterior com os espelhos que formam as paredes do aparelho, apresentam imagens diversas conforme o movimento. Para se observar as figuras agradáveis que o caleidoscópio pode formar é necessário movimentá-lo. Também, a imagem se forma se, e somente se, houver a interação dos elementos: fragmentos de espelhos por onde percorre a luz. Todos os elementos são extremamente necessários para que se tenha o resultado final. Outro símbolo que o ritmo evoca é a mandala, círculos que representam a dinâmica entre ser humano e cosmo, gravura sagrada que evoca meditação - basta pensar no movimento circular e complementar da "Ode" escolhida. Nas religiões hindus a mandala é feita por monges que se dedicam à feitura das mesmas por dias e dias, depois de prontas são santificadas e destruídas com a mesma fé com que foram feitas. Assim pode ser o texto poético: muito empenho para se fazer, por vezes alçando a patamares sacros, e, por fim, o resultado é verificar que sua finalidade é a destruição.

Os símbolos, pouco a pouco, vão ganhando força no percurso da autora. Assim também ocorre com os fragmentos. Mesmo nas primeiras publicações da autora a economia vocabular chama atenção, contudo, aos poucos, o volume de palavras vai se esmiuçando. Os versos compostos por cinco ou seis palavras vão se tornando versos com uma única palavra; os textos com cinco estrofes chegam a uma única; as alusões iniciais se tornam comentários entre parêntesis ou frases reticentes. O ritmo de leitura começa a ser mais recheado de pausas, se alonga, as supressões vão ganhando volume. A escrita fragmentada corrobora o ponto de vista que Antonio Candido tem em relação à autora, Orides Fontela "diz densamente muita coisa por meio de poucas, quase nenhuma, palavras" (CANDIDO apud FELIZARDO, 20096).

\footnotetext{
${ }^{6}$ Essa afirmação de Candido encontra-se nas orelhas da obra Trevo, livro organizado por Augusto Massi com poemas da autora de 1969 a 1988 .
} 
Os textos que permanecem em aberto, aparentemente inacabados, instauram o repouso, permitem infinitas possibilidades semânticas de modo mais consciente.

Todas essas ferramentas expostas aqui se encaminham para uma tentativa de marcar o silêncio. Este que é anterior à escrita, mais próximo do instante em que as sensações ocorrem. O silêncio marca o triunfo da renúncia, privilegiando o momento, a situação e menos a linguagem, uma vez que esta não é perfeita para representar o evento. Os espaços em branco apontam para novas direções, possibilitam que sejam preenchidos de forma eficaz. A palavra se torna um rizoma, rende mais que o previsto, multiplica-se, aponta para várias e diversas direções. A síntese da linguagem liga-se intimamente ao silêncio porque expande a crise da palavra apagando-a, ao apagá-la possibilita atingir o silêncio.

\section{Ondas silenciosas}

Refletir sobre o tema do silêncio na obra de Orides Fontela é um desafio. Pode até parecer óbvio, uma vez que o vocábulo é exaustivamente recuperado em sua trajetória literária. A própria poeta viveu a experiência do silêncio mantendo-se avessa aos círculos sociais, mantendo-se sozinha em seu silêncio.

Orides Fontela diz e rediz o que não pode ser dito. Um poema recupera o que ao outro escapou, mas, a este também escapa. Isso ocorre porque, assim como no som, uma vibração não é suficiente para sonorizar todas as possibilidades. $\mathrm{O}$ mesmo acontece com as palavras, ou seja, o signo verbal não abarca a diversidade do mundo. A poeta tem consciência disso. Contudo, nunca cessa seu trabalho em busca da melhor expressão por meio dessa ferramenta escorregadia que é a linguagem. Demonstra que sabe que a distância entre o fato e a linguagem é intransponível, mas permanece profanando o silêncio, dissolvendo-o em palavras.

\section{REFERÊNCIAS}

BLANCHOT, Maurice. O livro por vir. Tradução Leyla Perrone-Moisés. São Paulo: Martins Fontes, 2005.

. A literatura e o direito à morte. In: . A parte do fogo. Tradução de Ana Maria Scherer. Rio de Janeiro: Rocco, 2011, pp. 309-351. 
FARIA, Anaterra Gomes Engelhardt Barreto. Entre o verbo e o real inefável: Os modos do silêncio em Orides Fontela. [Monografia de Conclusão de Curso de Letras da Universidade Federal do Paraná]. Curitiba: 2014.

FELIZARDO, Alexandre Bonafim. Orides Fontela: A palavra entre o ser e o nada. In: VOOS Revista polidisciplinar eletrônica da faculdade guairacá. V. 1 (jul. 09). pp. 129-142. Disponível em: <http://www.revistavoos.com.br>. Acesso em 02/02/17.

FONTELA, Orides. Poesia Reunida [1969-1996]. São Paulo: Cosac Naify; Rio de Janeiro: 7 Letras, 2006.

BERGAMÍN, José. La decadencia del analfabetismo. In: La importância del demonio. Madrid: Suruela, 2006, pp. 21-58.

KAFKA, Franz. O silêncio das sereias. Folha de São Paulo, mai. 1984. Disponível em: < http://almanaque.folha.uol.com.br/kafka2.htm>. Acesso em 03/09/16.

LOPES, Marcos Aparecido. O canto e o silêncio na poética de Orides Fontela. In: Ipotesi. v. 12. n. 2. Juiz de Fora - MG: 2008, pp. $115-128$.

MANGANELLI, Giorgio. Rumori o Voci. Milano: Rizzoli, 1987.

ZILBERMAN, Regina. Poesia feminina em tempo de repressão. As mulheres que se expressaram nos anos 70 e 80. In: Signótica. v. 16. n. 1. pp. 143-169, jan./jun. 2004.

WISNIK, José Miguel. $O$ som e o sentido: uma outra história das músicas. São Paulo: Companhia das Letras, 1989.

Recebido em 14/08/2019. Aceito em 18/11/2019. 